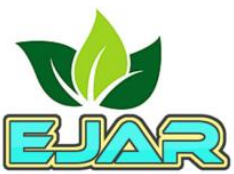

RESEARCH

\title{
Giza 97" A New Egyptian Long Staple Cotton Variety
}

\author{
Abdelbary, A. M.; H. M. Hamoud; W. M. Yehiya; A. M. Abdelmoghny (D)*; Eman, M. Rabi; Samia, E. Ali; \\ M. H. Orabi; Mariz, S. Max; M. S. Srour; Sawsan, E. Darwish; A. Zania; M. A. Raffat; Y. T. Atta; S. S. Attia; \\ H. M. Kotb; A, K. Attia and R. T. EL-Nawsany
}

\author{
Address: \\ Cotton Research Institute, Agricultural Research Center, 12619, Giza, Egypt \\ *Corresponding Author: A. M. Abdelmoghny elkomy_a@yahoo.com \\ Received: 03.08.2021; Accepted: 16.10.2021; Published: 25.10.2021
}

$10.21608 /$ ejar.2021.89116.1125

\section{ABSTRACT}

A new Egyptian cotton variety Giza 97 (Gossypium barbadense L.) accompanied by superior yield, fiber quality and resistance to Fusarium wilt (Fusarium oxysporum f. sp. vasinfectum) is developed by cotton breeding Section, Cotton Research Institute, Agricultural Research Center, Giza, Egypt. The new variety achieves targets for farmers (high yield, early maturity, resistance to pests and diseases), trader (high lint percentage), and spinner (good fiber quality). Also, had higher water use efficiency by saving $20 \%$ of irrigated water. Giza 97 originated from a cross between germplasm line [(Giza $89 \times$ R101) x Giza 86] and Giza 94. Starting from $F_{2}$ generation, the selection of a single plant was done using pedigree selection method. The superior combinations were finally selected at $F_{5}$ generation based on yield potential, fiber quality over the commercial varieties. Multilocations yield trials showed that these advanced lines had higher yield productivity plus maximum stability over five locations during two growing seasons and widely adapted in Delta region. During eight growing seasons Giza 97 was increasing significantly over the two commercial varieties (Giza 94 and Giza 86) over all locations The new variety characterized by 12.35 $\mathrm{K} / \mathrm{F}, 13.93 \mathrm{~K} / \mathrm{F}$ and $39.82 \%$ for seed cotton yield, lint yield and lint $\%$ traits. While, the fiber quality traits were characterized as a long staple cotton variety such as fiber length $(33.8 \mathrm{~mm})$, uniformity index ( $85.6 \%)$, micronaire value (4.4), fiber strength was (44.6 g/tex), yellowness or $+b$ (8.9) and yarn strength (2400) as the average mean during three growing seasons.

Keywords: Egyptian cotton, long staple, stability, Multilocations yield trials, GGE-biplot

\section{INTRODUCTION}

Egypt is one of the most leading countries in producing long and extra-long staple cotton in the world. The Egyptian cotton knows for its good fiber quality (fine, long and strength). The new varieties are generally the out-come of either a promising off-type selected out of an established variety for any particular improvement or a cross between two different varieties (AlDidi, 1972). Improving yield and fiber quality traits of Egyptian cotton by introducing new varieties is one of the most important objectives of Cotton Research Institute (CRI) in Egypt. The goal of introducing a new variety is to replace the current variety with a new one that shows significant improvement in productivity, quality and resistance to relevant diseases and pests, in addition, to match the requirements of the domestic and international textile industry.

The Egyptian cotton breeders using artificial hybridization to develop new varieties until now since 1912 and succeeded to produce 98 cotton varieties for commercial production. All these varieties are belonging to Gossypium barbadense L., and originated from crossing between older varieties or lines, except only one variety (Dandara) produced by direct selection from the field of Ashmouni variety (Al-Didi, 1972 and 1982). All the Egyptian varieties had the same name (Giza) then followed by a serial number. The main idea of the breeding program is a hybridization between two pure varieties or lines and continuous single plant selection from one generation to another accompanied by using selfed seeds for the selected plants for growing in the next season. The Egyptian cotton breeding program is developing new varieties with sustainable yield, early maturity and resistance to pests and diseases coupled with high fiber quality. These goals could achieve desirable targets for farmers, traders, spinner and breeders.

The Egyptian cotton breeders have directed more efforts towards enhancing yield for the long-staple (LS) cottons for the Delta region. The breeders were successful to increase the upper half mean length, uniformity index and strength for these cottons, that being characterized by the maximum length of the long-staple category. In addition, the strength level is close or near to the strength of the ELS cottons which enables the Delta LS cottons to compete with the extra-long staple (ELS) cottons in spinning performance and yarn quality.

The Egyptian cotton breeding program aims to produce highly productive varieties with higher fiber quality. To achieve this goal, the breeder tested several genotypes $(G)$ annually under different locations or environments (E), before isolation and 
multiplication and final recommendation. These experiments perform in farmer's fields trying to reduce the gap between productivity among experimental fields and farmer's fields. Mostly, these experiments had highly significant interactions between genotypes and environments (GEI). A good understanding of GEI provides a real impact of selection to ensure greater reliability when recommending genotypes to maximize yield productivity and other interested agronomic traits in a specific location or more locations (Farias et al., 2016). Most of the Egyptian cotton varieties are characterized by high yield productivity (seed cotton yield, lint yield and lint percentage), good fiber quality, and phenotypic stability. For this reason, it remains in general cultivation for a long time. Despite the importance of GEI did not present complete and accurate picture about the performance of the genotypes under different environments to the breeder. Therefore, it is necessary to identify the response of genotypes in specific or general conditions by analyzing adaptability and phenotypic stability (Yan et al., 2000 and Yan and Kang, 2003).

The breeding program focuses on most quantitative traits which had a greater effect on environmental effects. So, the breeder used different genetic analyses to analyze these traits to investigate the genetic behavior and genetic control of these traits. So, the breeder can select the best performing genotypes from breeding populations. The main goal is how to reduce environmental effect and increase fixed gene action (Yan and Kang, 2003). The selection changes the population genetic structure to maintain desirable alleles and discarding undesirable ones. The desirable alleles are a result of the recombination of superior alleles in different loci, so the breeder could select it during different breeding stages. Also, use heritability to estimate the amount of genetic variation which transfers from one generation to the next one that could help breeder to select the superior plants to improve genetic makeup of cotton plant (Abdelmoghny, 2021).

The cotton breeding program main objectives for long-staple (LS) cotton category are producing high yield, early maturity, resistance to diseases and pests, increased lint to seed ratio and widely adaption in Delta region. The Egyptian cotton breeder used GGE-biplot technique to select best cotton genotypes that contain both high productivity and stability undertested environments of Delta region.

\section{MATERIALS AND METHODS}

Development of new cotton variety is a result of intra-specific artificial hybridization between two cotton genotypes belonging to Gossypium barbadense L., [(Giza 89 x A101) x Giza 86] as a female parent characterized by high fiber strength and early maturity with Giza 94 as a male parent which is superior in seed cotton yield and lint percentage in the growing season of 2007 during the routine work of Egyptian cotton breeding program at Giza Experimental Research Station, Cotton Research Institute, Agricultural Research Center, Giza, Egypt. Then all the later generations, isolated field and production of breeder seeds were grown at Sakha Experimental Station, Agricultural Research Center, Kafr El-Sheikh governorate, Egypt.

$F_{1}$ generation was planted in the next season as individual plants and during flowering stage, self pollination was done to obtain the selfed seeds. The $F_{1}$ plants were picked and planted in the next season 2009 as individual plants to produce $F_{2}$ plants. Also, self-pollination was done at flowering stage. At maturity, all selfed and natural pollinated bolls of desirable single plants were picked from the whole $\mathrm{F}_{2}$ population. After laboratory work, the selection was done based on high yielding and good fiber quality plants. The natural bolls of the selected $F_{2}$ plants were planted as bulked families and selfed bolls of the same plant were planted as individual plants to produce $F_{3}$ generation in the growing season of 2010. At maturity, all selfed and natural pollinated bolls of desirable single plants and bulk families were picked, respectively from the selected $F_{3}$ families. After laboratory work, the superior families were selected beside their individual plants depending on high yielding and good fiber quality. Then, the selected individual plants from each family were planted as individual plants from selfed bolls and openpollinated bolls as bulk families to produce $\mathrm{F}_{4}$ generation in the 2011 season. The cotton breeder repeated the same selection process to promote for the next generations. Bulk family grown in a plot consists of three rows set of $4 \mathrm{~m}$ length, $70 \mathrm{~cm}$ apart and distance between plants within rows was $30 \mathrm{~cm}$. While individual plants were grown in two replicates each one consists of two rows set of $7 \mathrm{~m}$ in length, the distance between rows and plants was $70 \mathrm{~cm}$. In each generation, field selection was done on the basis of yield potential, plant height, plant architecture and subsequently reselected based on yield components estimates and fiber properties determined with both individual instruments for individual plants and high volume instruments (HVIs) for bulk families.

Six progeny lines were selected in 2013 for the preliminary trial A (LA) compare with the two commercial varieties (Giza 86 and Giza 94) in a randomized complete block design (RCBD) with six replications at Sakha experimental station, Kafr El-Sheikh governorate, Egypt. Then the seeds of the selected breeding lines from this experiment will be sown in the advanced or multi locations yield trial (LB) during two growing seasons 2014 and 2015 at five Egyptian governorates; Kafr El-Sheikh (E1), El-Gharbiya (E2), El-Sharquiya (E3), El-Dakahlia (E4) and El-Beheira (E5). These locations represented the most important cotton production area (Delta region) for long staple cotton category. The experimental design was a randomized complete block design (RCBD) with six replications in each location. Each entry was grown in a plot of five rows set of $4 \mathrm{~m}$ length, the distance was $70 \mathrm{~cm}$ between rows and $30 \mathrm{~cm}$ within plants. The experimental plot size was $14 \mathrm{~m}^{2}$. During the breeding program seasons and multi locations yield trials, all general agronomic and agricultural practices recommended for cotton crop production were adopted. 
Based on the results of multi locations yield trial the breeder decide to isolate this promising cross. The isolated field was grown at Sakha experimental station, Kafr El-Sheikh governorate in the growing season of 2016. This field must be characterized by $1 \mathrm{~km}$ far from other cotton fields from all directions to avoid cross-pollination and started with self-pollinated seeds only of 60 families, which grown as individual plants. These sixty families represent the mother families of the new variety Giza 97 . In the growing season of 2018, 2019 and 2020 the variety yield trial was done in a randomized complete block design with six replications. The plot consists of five rows, $4 \mathrm{~m}$ length; $70 \mathrm{~cm}$ distance between rows and $30 \mathrm{~cm}$ within plants with the total experimental plot size of $14 \mathrm{~m}^{2}$.

At harvest of all experiments (multi locations yield trails and variety yield trail), fifty bolls were collected from the two outer rows to measure average boll weight (BW) in grams. While, the three inner rows were harvested to estimate seed cotton yield (SCY) and lint yield (LY) which expressed in Kantar/Faddan (Kantar of seed cotton yield $=157.5 \mathrm{Kg}$, Kantar of lint yield $=50 \mathrm{Kg}$ and Faddan $=4200 \mathrm{~m}^{2}$ ). Fiber quality traits were estimated at Cotton Technology Laboratory, Cotton Research Institute, Agricultural Research Center, Giza, Egypt.

Analysis of variance (ANOVA) for boll weight, seed cotton yield and lint yield was done for each location separately. Then, combined analysis of variance was done using the mean data of each location for multi locations yield trial (LB). Bartlett test was used to determine the homogeneity of error variances between environments to determine the validity of the combined analysis of variance on the data as described by Gomez and Gomez, 1984. The GGE biplot was constructed based on the first two principal components (PCS) resulting from singular value decomposition (SVD), by estimating each element of the matrix through, also the multivariate graphical technique of GGE biplot was used to determine the stable genotypes as described by Yan et al., 2000 and Yan and Kang, 2003. Cluster analysis using multivariate analysis based on yield, its components and fiber quality traits using award's method was calculated as outlined by Johnson and Wichern 1998 to investigate the genetic similarity coefficient between sixteen nuclei using SPSS software.

\section{RESULTS}

The cotton breeder used multi locations yield trials (LB) to evaluate the best cotton crosses across five locations (Kafr El-Sheikh (E1), El-Gharbiya (E2), El-Sharquiya (E3), El-Dakahlia (E4) and El-Beheira (E5)), which represent cotton-growing area (Delta region) for long-staple category compared with the two commercial varieties of this category (Giza 86 and Giza 94). These trials were established in farmer's fields to reduce the gap between yield potential by farmers and those obtained from experimental stations which using all the best managements. During 2014 and 2015 multi locations yield trials (LB) consists of the best eight cotton crosses in the breeding program plus two commercial varieties, which were evaluated under five locations. The target of this trial is to select the best cotton cross which had both higher yield productivity over two commercial varieties with high stability and characterized by good fiber quality in the range of long-staple cotton category.

Firstly, the breeder tests homogeneity of experimental errors using Bartlett's test as described by Gomez and Gomez, 1984. The results showed homogeneity of such errors. Then the results of combined analysis of variance across locations and growing seasons for the ten cotton genotypes revealed that there were highly significant $(P<0.01)$ differences between five locations $(E)$, two seasons $(Y)$ and among ten genotypes $(G)$ for lint yield $(K / F)$ as showing in Table 1. Also, the interaction between $G \times E, Y \times E$ and $Y \times G$ was significant for lint yield trait.

Phenotypic mean performances for the studied ten cotton genotypes under five locations during two growing seasons for lint yield (K/F) are presented in Table 2. The results showed that the studied genotypes ranged from $10.8 \mathrm{~K} / \mathrm{F}$ to $13.5 \mathrm{~K} / \mathrm{F}$ in 2014 growing seasons and from 11.9 K/F to 14.0 K/F in 2015 for Giza 86 (G10) and [(Giza 89 x A101) x Giza 86] x Giza 94 (G2), respectively. The cross [(Giza $89 \times$ A101) x Giza 86] x Giza 94 has the highest values of lint yield than the other crosses and the two commercial varieties over years and locations; 14.2, 13.6, 13.4, 14.7 and 13.0 K/F in Kafr El-Sheikh (E1), El-Gharbiya (E2), El-Sharquiya (E3), El-Dakahlia (E4) and El-Beheira (E5), respectively (Figure 1). While, average lint \% was $40.1 \%$ under five locations during two growing seasons, which similar or near to Giza 94 but was higher than Giza 86 (38.6\%). On the other hand, fiber quality traits for the ten genotypes were in the range of long staple cotton category. So, the breeder main goal for this category is increasing yield, its components, maturity and maintains fiber quality in the range of this category.

Table 1: Combined analysis of variance for ten cotton genotypes during two growing seasons over five locations for lint yield $\mathrm{K} / \mathrm{F}$

\begin{tabular}{|c|c|c|c|}
\hline \multicolumn{3}{|c|}{ Mean squares } & \multirow{2}{*}{ Variation \% } \\
\hline SOV & d.f & Lint yield & \\
\hline Replications & 5 & 0.2668 & \\
\hline Environments (E) & 4 & $13.8783^{* *}$ & 34.22 \\
\hline Years (Y) & 1 & $12.8433^{* *}$ & 7.92 \\
\hline Genotypes (G) & 9 & $0.6900^{* *}$ & 3.83 \\
\hline$E \times Y$ & 4 & $8.4808^{* *}$ & 20.91 \\
\hline Ex G & 36 & $0.1706 * *$ & 3.79 \\
\hline Y X G & 9 & $0.1720^{*}$ & 0.95 \\
\hline$E \times Y \times G$ & 36 & 0.0729 & 1.62 \\
\hline Error & 495 & 0.0850 & 25.95 \\
\hline
\end{tabular}


Table 2. Mean performance for the ten cotton crosses during two seasons over five locations for lint yield K/F

\begin{tabular}{|c|c|c|c|c|c|c|c|c|c|c|c|c|c|}
\hline \multirow{2}{*}{$\begin{array}{c}\text { Seasons } \\
\text { Locations } \\
\text { Genotypes }\end{array}$} & \multicolumn{6}{|c|}{ Season of 2014} & \multicolumn{6}{|c|}{ Season of 2015} & \multirow[b]{2}{*}{$\begin{array}{l}\text { Grano } \\
\text { mean }\end{array}$} \\
\hline & E1 & E2 & E3 & E4 & E5 & Mean & E1 & E2 & E3 & E4 & E5 & Mean & \\
\hline \multirow{2}{*}{ G1 } & \multicolumn{13}{|c|}{ (Giza 89 x Giza 86) x \{[Bahtim 105 x Giza 67) x (Giza 72 x P102)] x (Giza 89 x Giza 86)\} } \\
\hline & 14.1 & 13.4 & 12.1 & 13.7 & 12.5 & 13.2 & 11.5 & 13.9 & 11.6 & 14.2 & 14.6 & 13.1 & 12.9 \\
\hline \multirow{2}{*}{ G2 } & \multicolumn{13}{|c|}{ [(Giza 89 x A101) x Giza 86] x Giza 94} \\
\hline & 14.7 & 13.3 & 13.8 & 14.7 & 11.4 & 13.6 & 13.6 & 13.9 & 13.0 & 14.7 & 14.7 & 14.0 & 13.7 \\
\hline \multirow{2}{*}{ G3 } & \multicolumn{13}{|c|}{ [(Giza 85 x S107) x Giza 86] x [(Giza 89 x A101) x Giza 86] } \\
\hline & 14.7 & 13.3 & 12.1 & 14.7 & 11.4 & 13.2 & 11.5 & 13.9 & 11.6 & 14.2 & 14.6 & 13.1 & 13.2 \\
\hline \multirow{2}{*}{ G4 } & \multicolumn{13}{|c|}{ (Giza 89 x S106) x D101 } \\
\hline & 14.2 & 12.8 & 12.3 & 13.6 & 10.4 & 12.7 & 13.0 & 14.4 & 13.1 & 13.6 & 13.9 & 13.6 & 13.1 \\
\hline \multirow{2}{*}{ G5 } & \multicolumn{13}{|c|}{ (Giza 89 x S106) x \{[Bahtim 105 x Giza 67) x (Giza 72 x D101)] x (Giza 89 x Giza 86)\} } \\
\hline & 14.5 & 11.4 & 12.4 & 13.5 & 10.2 & 12.4 & 14.4 & 13.0 & 14.5 & 14.6 & 13.0 & 13.9 & 13.1 \\
\hline \multirow{2}{*}{ G6 } & \multicolumn{13}{|c|}{ (Giza 85 x Giza 86) x [( Giza 83 x Giza 80) x Giza 89] } \\
\hline & 14.9 & 12.6 & 13.0 & 14.0 & 12.4 & 13.4 & 12.7 & 13.6 & 12.1 & 14.3 & 11.8 & 12.9 & 13.1 \\
\hline \multirow{2}{*}{ G7 } & \multicolumn{13}{|c|}{ Giza 85 x (Giza 89 x Giza 86) } \\
\hline & 13.7 & 12.8 & 12.4 & 13.0 & 11.3 & 12.6 & 13.2 & 14.3 & 12.2 & 13.5 & 12.6 & 13.1 & 12.9 \\
\hline \multirow{2}{*}{ G8 } & \multicolumn{13}{|c|}{ [Giza 83 x (Giza 85 x S106)] x Giza 89} \\
\hline & 12.7 & 11.0 & 13.6 & 14.0 & 10.4 & 12.3 & 10.8 & 14.8 & 12.4 & 14.2 & 13.0 & 13.0 & 12.7 \\
\hline \multirow{2}{*}{ G9 } & \multicolumn{13}{|c|}{ Giza 94} \\
\hline & 11.8 & 12.4 & 11.6 & 13.2 & 11.5 & 12.1 & 12.2 & 14.1 & 11.2 & 12.9 & 12.8 & 12.7 & 12.4 \\
\hline \multirow{2}{*}{ G10 } & \multicolumn{13}{|c|}{ Giza 86} \\
\hline & 10.4 & 10.2 & 11.1 & 12.3 & 10.3 & 10.8 & 11.2 & 13.7 & 10.6 & 13.2 & 11.0 & 11.9 & 11.4 \\
\hline E means & 13.5 & 12.3 & 12.4 & 13.4 & 11.1 & 12.6 & 12.5 & 13.9 & 12.2 & 14.0 & 13.2 & 13.2 & \multirow[t]{2}{*}{12.9} \\
\hline Years mean & \multicolumn{6}{|c|}{12.6} & & & & & & & \\
\hline LSD at & & & 5 prob & ability I & vel & & & & 0.0 & orobal & lity lev & & \\
\hline$E$ & & & & 993 & & & & & & 0.1 & & & \\
\hline $\mathbf{Y}$ & & & & 059 & & & & & & 0.0 & & & \\
\hline G & & & & 131 & & & & & & 0.1 & & & \\
\hline EXY & & & & 131 & & & & & & 0.1 & & & \\
\hline ExG & & & & 294 & & & & & & 0.3 & & & \\
\hline$Y \times G$ & & & & 186 & & & & & & 0.2 & & & \\
\hline$E \times Y \times G$ & & & & 416 & & & & & & 0.5 & & & \\
\hline
\end{tabular}

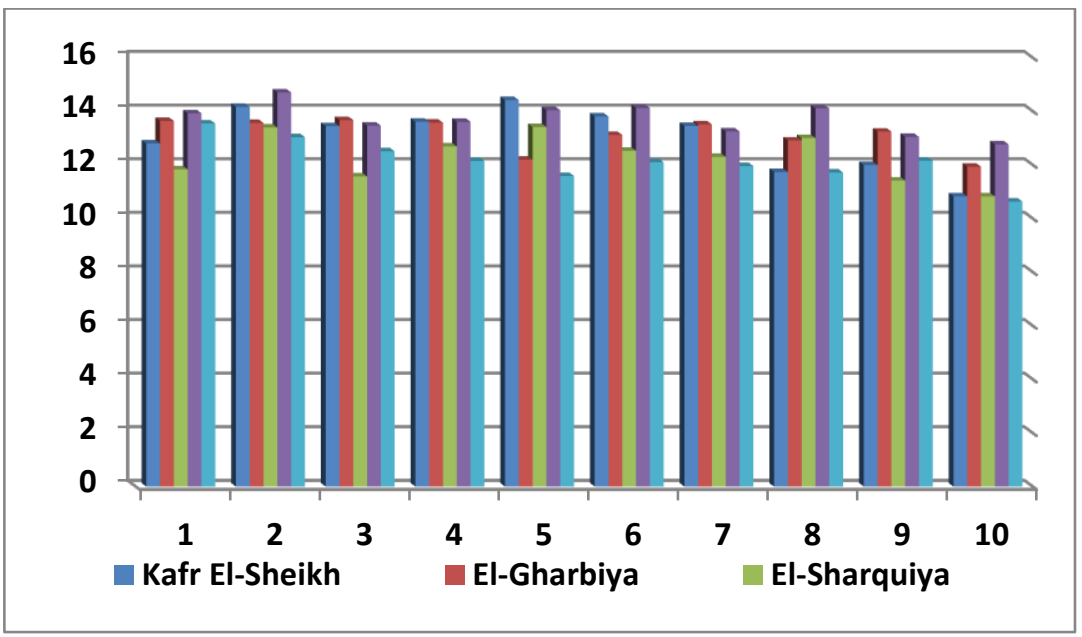

Figure 1: Performance of ten genotypes during two growing seasons over five locations for lint yield K/F

The variations were partition to its components; genotypes, environments, years and their interactions as presented in Table 1. The variation was $3.83 \%, 34.22 \%, 7.92 \%$ and $3.79 \%$ for genotypes, environments, years and GEl, respectively. Also, the results of GGE-biplot had $69.22 \%$ and $16.25 \%$ for PCA 1 and PCA 2, respectively with a total variation of $85.74 \%$ for lint yield (K/F). Similar results showed a higher environmental effect on lint cotton yield obtained by Abd El-Moghny and Max, 2015 and Abdelmoghny et al., 2019 and 2020. 
The GGE-biplot polygon was used to identify the best genotypes and mega-environments as shown in Figure 2 . The best genotypes which located in the polygon vertices to form the perpendicular are 1, 2, 4, 5, 9 and 10. The biplot classified the five environments into two mega-environments (E2 and E4) and (E1 and E3). Genotypes 2, 3 and 4 located in the first megaenvironment and genotypes 1 and 6 are suitable for the second mega-environment. So, these genotypes will produce high lint yield $(K / F)$ in these locations than others. The two-dimensional graph used to identify genotypes based on yield and stability depending on average environments coordinates (Figure 3). The line with one arrow and pass across small circle (environments mean) and the origin point used to estimate genotype mean performance and stability. Yan and Kang, 2003 reported that the genotypes located on the right side had higher lint yield, while genotypes close to the axis was more stable. Genotypes 2, 3 and 7 fall in the right side and very close to the axis had the higher lint yield and more stable. Genotypes 1, 4 and 6 had higher lint yield than other genotypes but still less stable. While, the genotype 8 fall in the left side and close to the axis is the lowest lint yield but still stable. On the other hand, the two varieties Giza 86 (G10) and Giza 94 (G9) had low lint yield than the overall mean performance $(12.9 \mathrm{~K} / \mathrm{F})$ but still stable.

The GGE-biplot rank genotypes based on the ideal genotype and ideal environments using stability and high lint yield performance. Yan and Kang, $\mathbf{2 0 0 3}$ defined ideal genotype as the genotype which has both high yield performance, maximum stability and located on the concentric circle of the biplot. While, the ideal environment located on the first concentric circle in the biplot. Any genotype near to the ideal genotype and any environment near to ideal environment is deified as the desirable genotype or desirable environment, respectively. Genotype [(Giza 89 x A101) x Giza 86] x Giza 94 (G2) is known as the ideal genotype and the genotypes G1, G3, G4 and G6 are the desirable ones. E5 is the ideal environment and E1, E2 and E3 are the desirable environments (Figure 4).

One advantage of the Egyptian cotton breeding program is annually an evaluation of new promising cross (G 2) with the two commercial varieties through multi locations yield trails (LB). So, during seven growing seasons from 2014 to 2020, the breeder compares the new promising cross [(Giza 89 x A101) x Giza 86] x Giza 94 with two commercial varieties of the longstaple category. The comparsion between the three cotton genotypes for seed cotton yield (K/F), lint yield (K/F) and lint \% showed that that the new genotype had higher values for yield traits than the two commercial varieited as presented in Figures $5,6,7$.

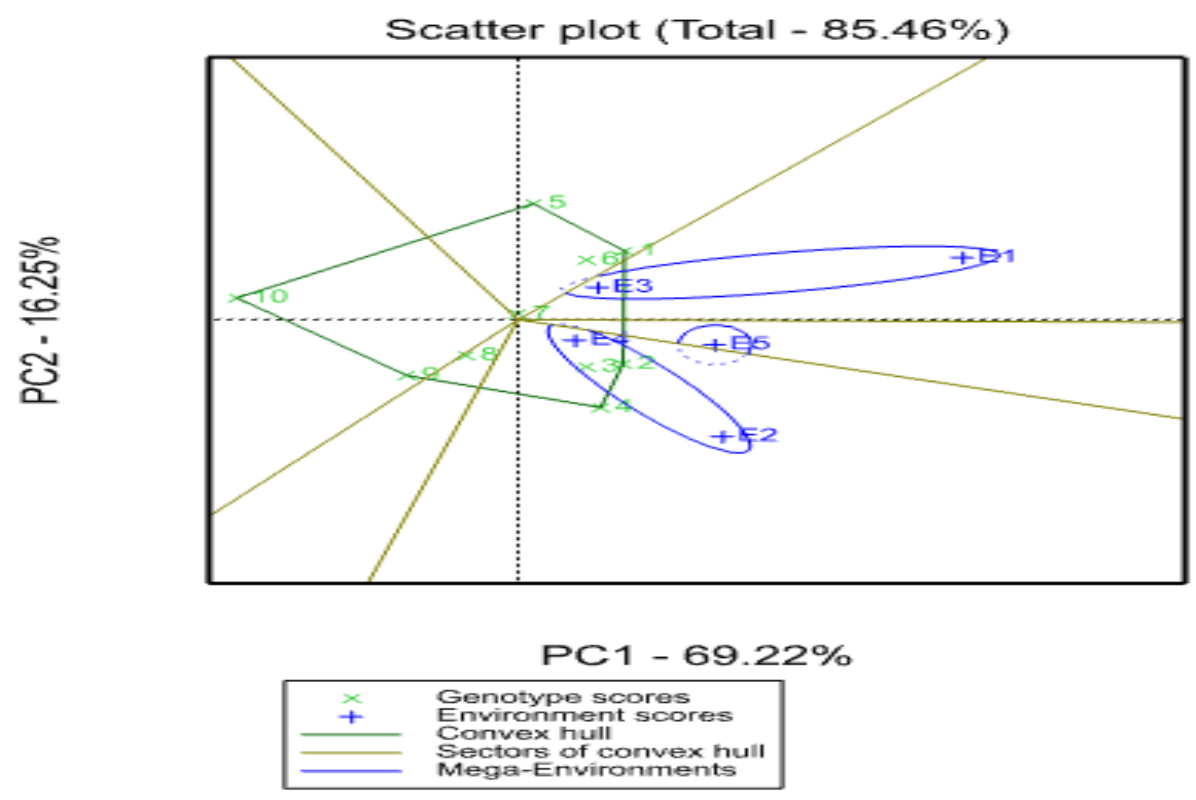

Figure 2: Polygon view of GGE-biplot technique to dentify the best genotype under mega-environments 


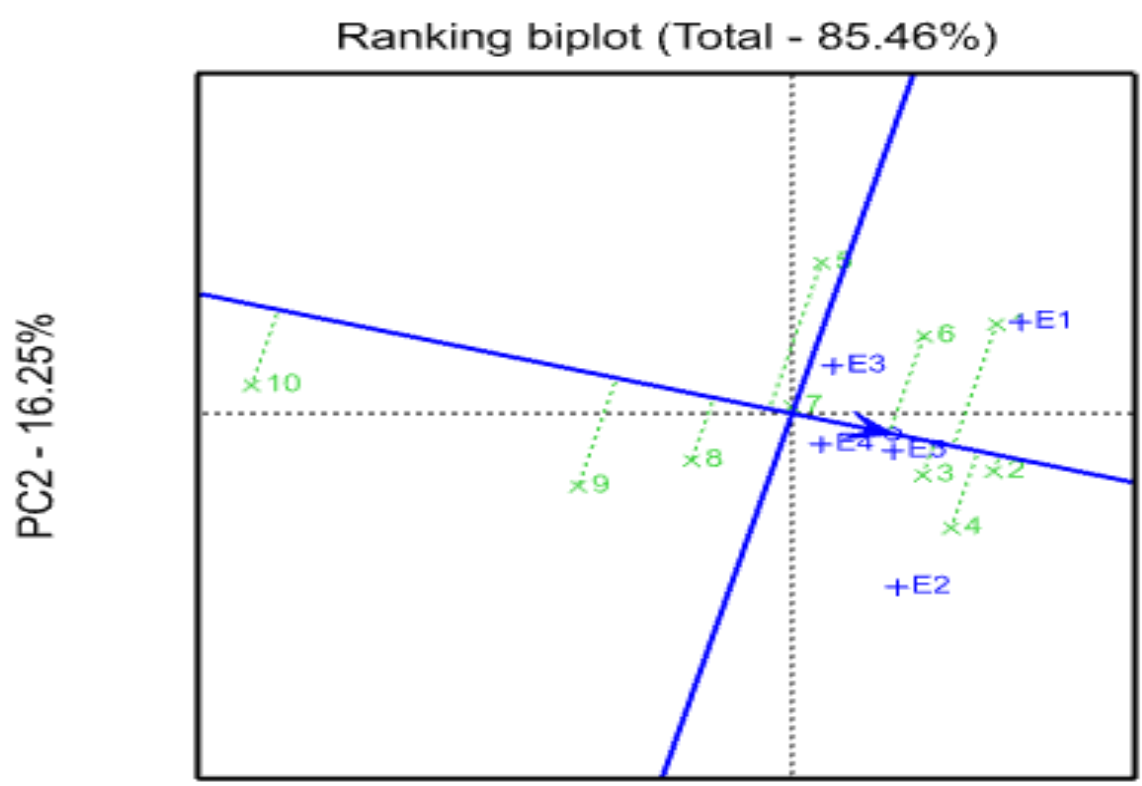

PC1 - 69.22\%

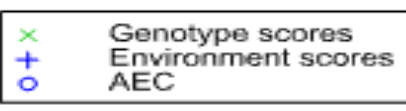

Figure 3: Evaluation of lint cotton yield and stability for the ten genotypes under five environments using GGE-biplot technique Comparison biplot (Total - 85.46\%)

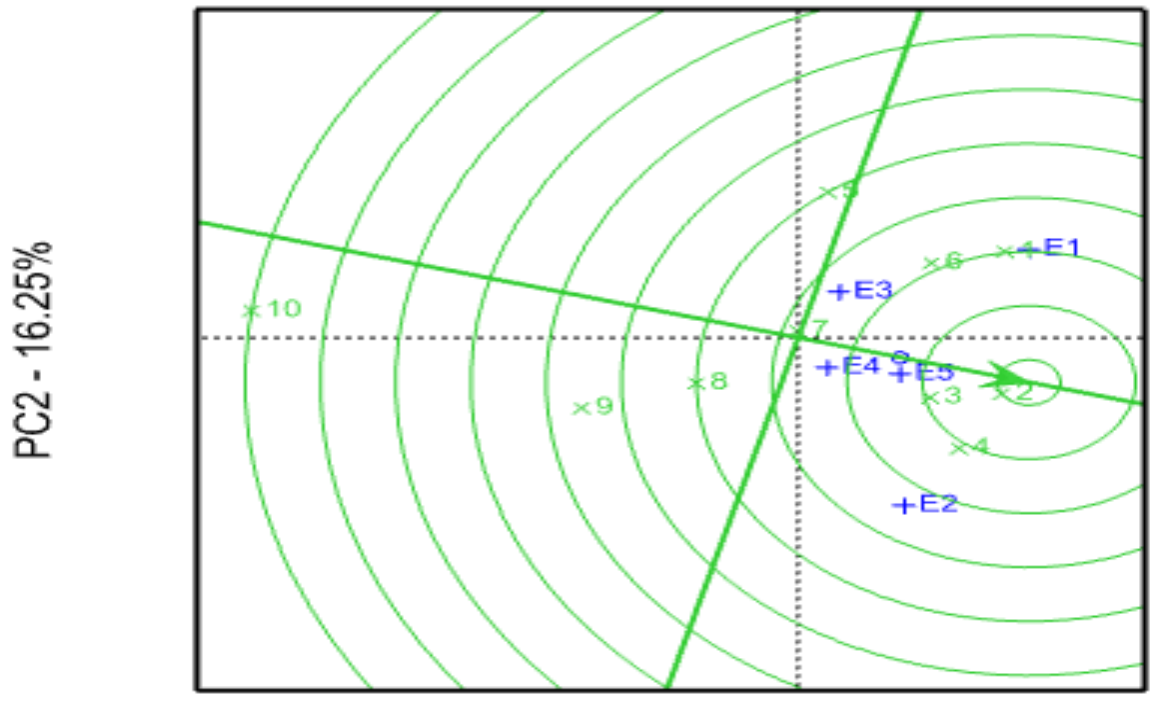

PC1 - 69.22\%

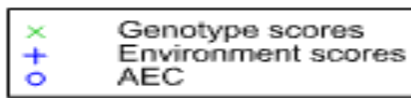

Figure 4: GGE-biplot for comparison of all the genotypes with the ideal genotype 


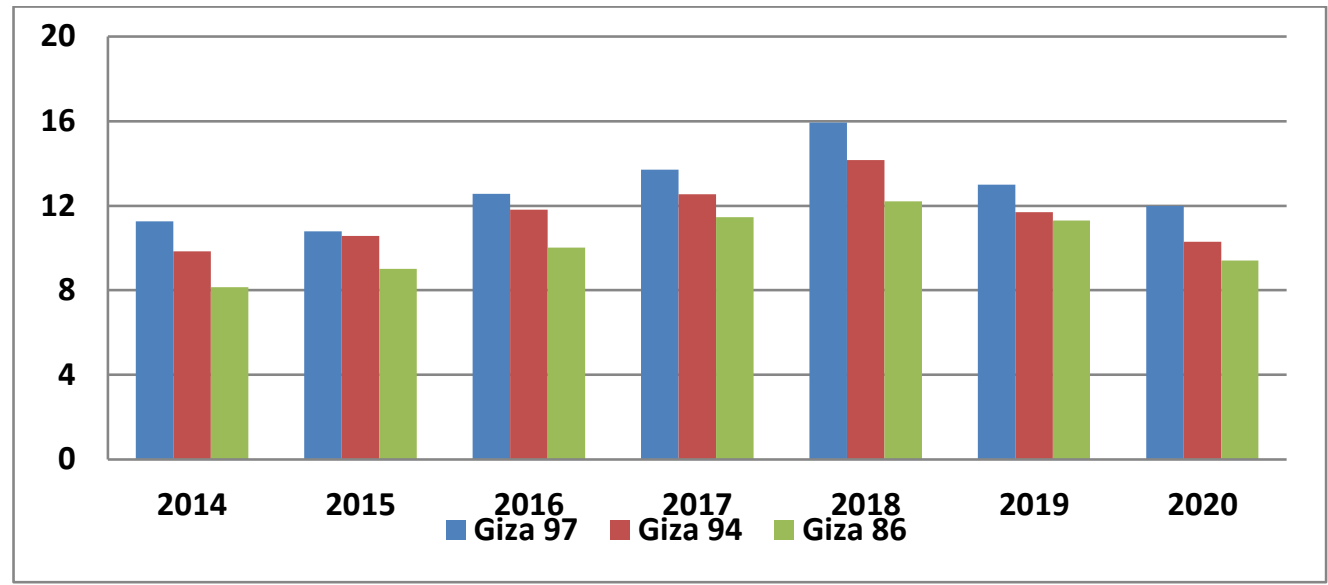

Figure 5: Compersion between Giza 97 and two commerical varieties (Giza 86 and Giza 94) during seven growing seasons over five locations for seed cotton yield $\mathrm{K} / \mathrm{F}$

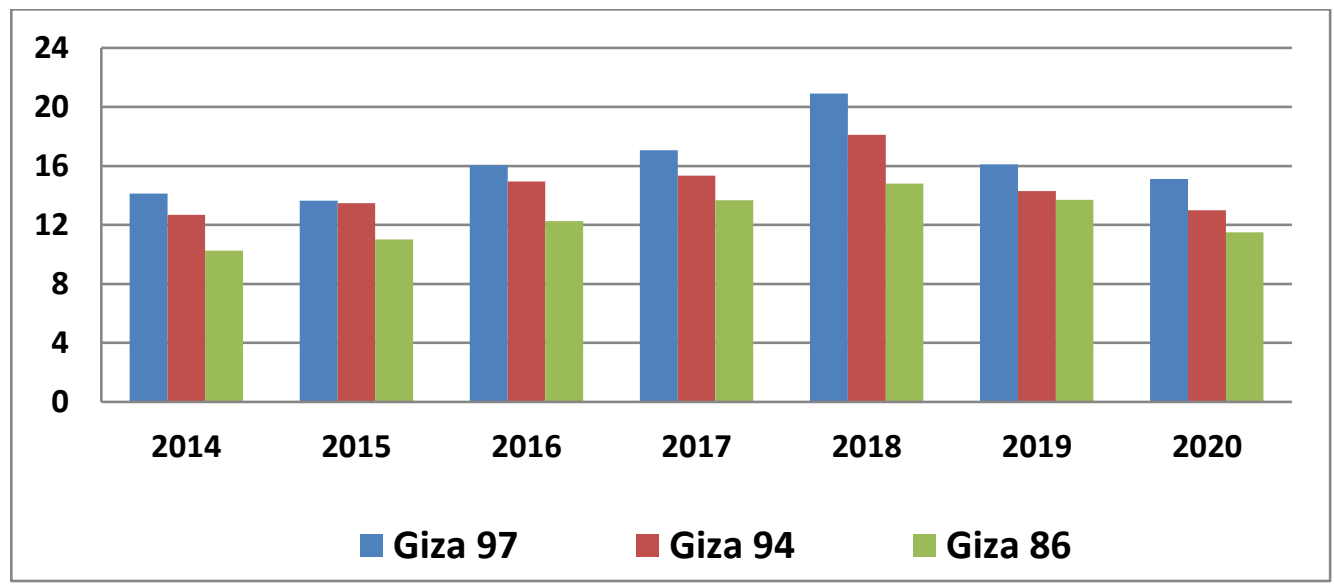

Figure 6: Compersion between Giza 97 and two commerical varieties (Giza 86 and Giza 94) during seven growing seasons over five locations for lint yield $\mathrm{K} / \mathrm{F}$

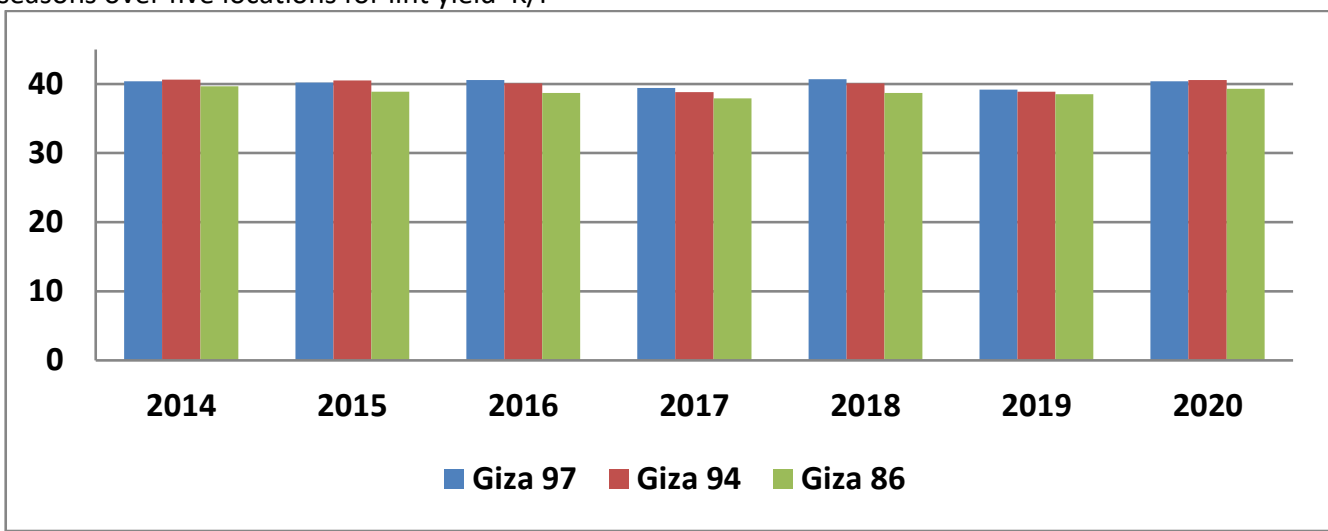

Figure 7: Compersion between Giza 97 and two commerical varieties (Giza 86 and Giza 94) during seven growing seasons over five locations for lint \%

During three growing seasons (2018, 2019 and 2020) the breeder evaluated sixteen nuclei in a randomized complete block design (RCBD) with six replications as the variety yield trial with five rows in each plot (the plot size was $14 \mathrm{~m}^{2}$ ). The main purpose of this trial is to test homogeneity and uniformity between the sixteen nuclei. The combined analysis of variance showed that the variation between sixteen nuclei and their interaction with environments (GEI) was insignificant, but years was highly significant (Table 3). According to these results, the breeders select some nuclei which had superiority of their yield and fiber quality higher than the overall mean and mixed to perform breeder seed. The average mean performance for fiber quality traits during three growing seasons is presented in Table 4. The new variety Giza 97 is characterized by fiber length $(33.8 \mathrm{~mm})$, uniformity index (85.6\%), micronaire value (4.4), fiber strength was (44.6 g/tex), yellowness or +b (8.9) and yarn strength (2400). Also, the breeder used cluster analysis based on Ward's method to investigate genetic distance and diversity between the sixteen nuclei. The data matrix of the similarity coefficient based on Pearson correlation is given in Table $\mathbf{5}$. The 
similarity coefficient was very high and ranged from 1.00 between $(2,8),(3,6),(3,7),(3,11),(6,7),(6,11),(7,11)$ and $(10,14)$ to 0.91 between $(4,13),(8,14)$ and $(12,13)$. The mean performance of the sixteen nuclei were $12.36,12.29$ and 12.39 for seed cotton yield (K/F), 13.96, 13.86 and 13.97 for lint yield (K/F) and 39.85\%, 40.04\% and $39.56 \%$ for lint \% during the three growing seasons (2018, 2019 and 2020) as shown in Figures 8, 9 and 10, respectively. On the other hand, fiber quality traits were characterized as a long-staple cotton variety and had non-significant differences for the sixteen nuclei over three growing seasons.

Table 3: Analysis of variance for Giza 97 yield trial during three growing seasons for yield traits

\begin{tabular}{|c|c|c|c|c|}
\hline \multicolumn{5}{|c|}{ Mean squares } \\
\hline Sov & d.f & Boll weight BW & Seed cotton yield SCY & Lint yield LY \\
\hline Replications & 5 & 0.022 & 4.949 & 4.682 \\
\hline Treatments & 47 & 0.133 & 1.544 & 2.314 \\
\hline Years (A) & 2 & 0.499 & $12.153^{* *}$ & $29.338 * *$ \\
\hline Nucleus (B) & 15 & $0.069^{\mathrm{Ns}}$ & $1.167^{\mathrm{Ns}}$ & $1.397^{\mathrm{Ns}}$ \\
\hline$A \times B$ & 30 & $0.149^{\mathrm{Ns}}$ & $1.021^{\mathrm{Ns}}$ & $0.977^{\mathrm{Ns}}$ \\
\hline Error & 235 & 0.022 & 1.3 & 1.695 \\
\hline
\end{tabular}

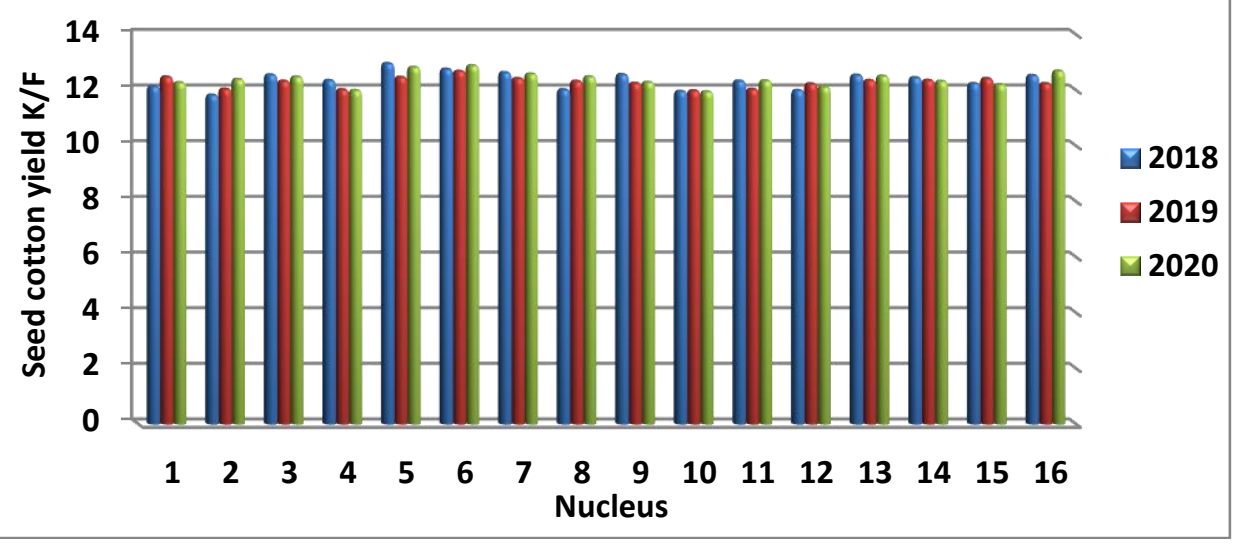

Figure 8: Sixteen nucleus of Giza 97 during three growing seasons for seed cotton yield K/F

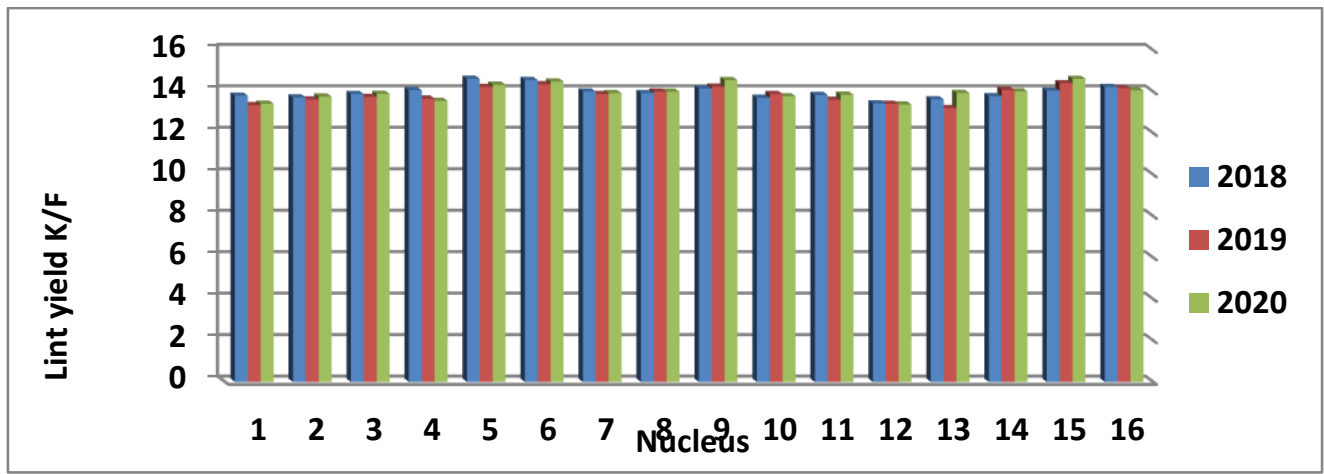

Figure 9: Sixteen nucleus of Giza 97 during three growing seasons for lint yield K/F

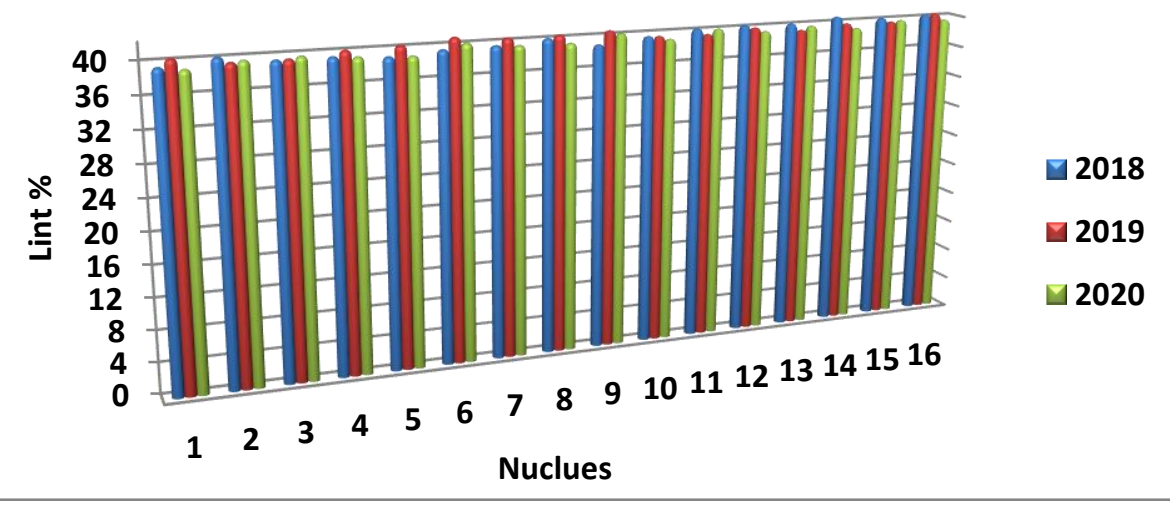

Figure 10: Sixteen nucleus of Giza 97 during three growing seasons for lint \% 
Table 4: Phenotypic mean performance for fiber quality traits for the sixteen nucleus of Giza 97 during three growning seasons

\begin{tabular}{|c|c|c|c|c|c|c|c|c|}
\hline Nuclei & $\begin{array}{c}\text { Fiber } \\
\text { length } \\
\mathbf{m m}\end{array}$ & $\begin{array}{c}\text { Uniformity } \\
\text { index } \\
\mathbf{\%}\end{array}$ & $\begin{array}{c}\text { Fiber } \\
\text { strength } \\
\text { g/tex }\end{array}$ & $\begin{array}{c}\text { Micronaire } \\
\text { reading }\end{array}$ & Maturity & RD & +b & $\begin{array}{c}\text { Yearn } \\
\text { strength }\end{array}$ \\
\hline $\mathbf{1}$ & 33.8 & 84.6 & 45.2 & 4.4 & 1.0 & 73.5 & 8.8 & 2400 \\
\hline $\mathbf{2}$ & 34.3 & 85.3 & 45.2 & 4.4 & 0.9 & 74.2 & 9.0 & 2460 \\
\hline $\mathbf{3}$ & 34.2 & 85.8 & 43.7 & 4.4 & 0.9 & 75.0 & 9.4 & 2400 \\
\hline $\mathbf{4}$ & 33.9 & 85.3 & 44.8 & 4.5 & 1.0 & 74.9 & 8.8 & 2340 \\
\hline $\mathbf{5}$ & 34.0 & 86.0 & 45.7 & 4.4 & 1.0 & 73.2 & 8.4 & 2400 \\
\hline $\mathbf{6}$ & 33.8 & 85.9 & 45.2 & 4.4 & 1.0 & 75.6 & 8.6 & 2400 \\
\hline $\mathbf{7}$ & 33.5 & 86.2 & 45.1 & 4.5 & 1.0 & 74.2 & 8.9 & 2340 \\
\hline $\mathbf{8}$ & 33.6 & 85.2 & 43.8 & 4.5 & 1.0 & 75.1 & 9.0 & 2400 \\
\hline $\mathbf{9}$ & 34.3 & 84.8 & 44.8 & 4.2 & 0.9 & 72.8 & 9.0 & 2460 \\
\hline $\mathbf{1 0}$ & 33.6 & 85.3 & 45.3 & 4.4 & 1.0 & 76.8 & 9.0 & 2280 \\
\hline $\mathbf{1 1}$ & 33.1 & 84.0 & 43.9 & 4.4 & 1.0 & 74.4 & 9.4 & 2400 \\
\hline $\mathbf{1 2}$ & 33.5 & 85.0 & 43.3 & 4.5 & 0.9 & 73.2 & 9.3 & 2480 \\
\hline $\mathbf{1 3}$ & 34.6 & 86.4 & 45.6 & 4.4 & 1.0 & 75.3 & 9.3 & 2480 \\
\hline $\mathbf{1 4}$ & 33.7 & 85.3 & 45.3 & 4.5 & 1.0 & 74.6 & 9.0 & 2360 \\
\hline $\mathbf{1 5}$ & 33.3 & 85.8 & 44.7 & 4.4 & 1.0 & 75.7 & 9.2 & 2460 \\
\hline $\mathbf{1 6}$ & 34.1 & 86.3 & 44.3 & 4.5 & 1.0 & 74.8 & 8.7 & 2400 \\
\hline Mean & $\mathbf{3 3 . 8}$ & $\mathbf{8 5 . 4}$ & $\mathbf{4 4 . 7}$ & $\mathbf{4 . 4}$ & $\mathbf{0 . 9 8}$ & $\mathbf{7 4 . 5}$ & $\mathbf{8 . 9}$ & $\mathbf{2 4 0 3}$ \\
\hline Var & $\mathbf{0 . 1 6}$ & $\mathbf{0 . 4 4}$ & $\mathbf{0 . 5 3}$ & $\mathbf{0 . 0 1}$ & $\mathbf{0 . 0 0}$ & $\mathbf{1 . 1 2}$ & $\mathbf{0 . 0 8}$ & $\mathbf{3 1 0 5}$ \\
\hline SE & $\mathbf{0 . 1 0}$ & $\mathbf{0 . 1 7}$ & $\mathbf{0 . 1 8}$ & $\mathbf{0 . 0 2}$ & $\mathbf{0 . 0 1}$ & $\mathbf{0 . 2 6}$ & $\mathbf{0 . 0 7}$ & $\mathbf{1 3 . 9 3}$ \\
\hline
\end{tabular}

Table 5: Similarity coefficient between sixteen nuclei based on yield, its components and fiber quality traits

\begin{tabular}{|c|c|c|c|c|c|c|c|c|c|c|c|c|c|c|c|c|}
\hline Nuclei & $\mathbf{1}$ & $\mathbf{2}$ & $\mathbf{3}$ & $\mathbf{4}$ & $\mathbf{5}$ & $\mathbf{6}$ & $\mathbf{7}$ & $\mathbf{8}$ & $\mathbf{9}$ & $\mathbf{1 0}$ & $\mathbf{1 1}$ & $\mathbf{1 2}$ & $\mathbf{1 3}$ & $\mathbf{1 4}$ & $\mathbf{1 5}$ & $\mathbf{1 6}$ \\
\hline $\mathbf{1}$ & 1.00 & & & & & & & & & & & & & & & \\
\hline $\mathbf{2}$ & 0.95 & 1.00 & & & & & & & & & & & & & & \\
\hline $\mathbf{3}$ & 0.95 & 0.97 & 1.00 & & & & & & & & & & & & & \\
\hline $\mathbf{4}$ & 0.96 & 0.93 & 0.98 & 1.00 & & & & & & & & & & & & \\
\hline $\mathbf{5}$ & 0.94 & 0.95 & 0.99 & 0.99 & 1.00 & & & & & & & & & & & \\
\hline $\mathbf{6}$ & 0.97 & 0.99 & 1.00 & 0.97 & 0.99 & 1.00 & & & & & & & & & & \\
\hline $\mathbf{7}$ & 0.95 & 0.97 & 1.00 & 0.98 & 0.99 & 1.00 & 1.00 & & & & & & & & & \\
\hline $\mathbf{8}$ & 0.96 & 1.00 & 0.97 & 0.93 & 0.95 & 0.99 & 0.97 & 1.00 & & & & & & & & \\
\hline $\mathbf{9}$ & 0.92 & 0.96 & 0.99 & 0.96 & 0.97 & 0.98 & 0.99 & 0.96 & 1.00 & & & & & & & \\
\hline $\mathbf{1 0}$ & 0.95 & 0.97 & 0.99 & 0.96 & 0.96 & 0.99 & 0.99 & 0.99 & 0.99 & 1.00 & & & & & & \\
\hline $\mathbf{1 1}$ & 0.94 & 0.97 & 1.00 & 0.97 & 0.99 & 1.00 & 1.00 & 0.97 & 0.99 & 0.98 & 1.00 & & & & & \\
\hline $\mathbf{1 2}$ & 0.98 & 0.98 & 0.98 & 0.96 & 0.95 & 0.99 & 0.98 & 0.99 & 0.97 & 0.99 & 0.97 & 1.00 & & & & \\
\hline $\mathbf{1 3}$ & 0.90 & 0.93 & 0.96 & 0.91 & 0.94 & 0.95 & 0.95 & 0.91 & 0.96 & 0.92 & 0.97 & 0.91 & 1.00 & & & \\
\hline $\mathbf{1 4}$ & 0.92 & 0.96 & 0.98 & 0.95 & 0.96 & 0.98 & 0.98 & 0.97 & 0.99 & 1.00 & 0.97 & 0.98 & 0.92 & 1.00 & & \\
\hline $\mathbf{1 5}$ & 0.92 & 0.96 & 0.97 & 0.93 & 0.93 & 0.97 & 0.97 & 0.98 & 0.99 & 0.99 & 0.96 & 0.98 & 0.93 & 0.99 & 1.00 & \\
\hline $\mathbf{1 6}$ & 0.94 & 0.98 & 0.99 & 0.97 & 0.99 & 0.99 & 0.99 & 0.98 & 0.97 & 0.98 & 0.99 & 0.97 & 0.92 & 0.97 & 0.95 & 1.00 \\
\hline This is a similarity matrix & \multicolumn{8}{|c|}{}
\end{tabular}

\section{DISCUSSIONS}

The Egyptian cotton breeding program is depending on intra-specific artificial hybridization to produce new varieties then using the pedigree selection method. The pedigree selection method produce relatively uniform lines and should focus only on highly heritable and easily scored traits (Fehr, 1987). During early generations, the breeder estimates variance between families, within families, broad and narrow sense heritability and genetic gain. So, selection during these generations is based on narrow sense heritability coupled with genetic gain to select the best families and superior plants within each family (Abdelmoghny, 2021 and Gibely, 2021 a). The main aim during these segregating generations is reducing genetic variability between families to increase additive gene action or producing pure lines. So, the cotton breeder hybridizes [(Giza $89 \times$ A101) x Giza 86] as a female parent characterized by the good fiber quality and early maturity traits and Giza 94 as a male parent which had high yield productivity and high lint $\%$ to produce $F_{1}$ seeds in the growing season of 2007 . The hybrid seeds were planted in the growing season of 2008 to produce the $F_{1}$ plants. The target of this cross to produce a new genotype had high seed cotton yield, lint yield, lint \% and good fiber quality traits coupled with early maturity. So, the breeder used these traits as selection indies during all generations especially segregating generations.

In the growing season of 2009 the selfed seeds of the $F_{2}$ generation were grown and the breeder estimate transgressive segregation to select the best plants which exceed better parent in all traits. The progeny of each selected plant is grown separately which constitutes $F_{3}$ generation. Through $F_{3}$ and $F_{4}$ generations, selection is practiced within and between families. Selection was predicated from $F_{5}$ to $F_{8}$ generations between progenies and compared with the two commercial varieties (Giza 86 and Giza 94) belonging to this cotton category. These advanced strains or lines are evaluated in replicated 
multi-locations yield trials for two growing seasons (2014 and 2015) to estimate productivity and stability. Then the superior progeny which characterized by high yield with maximum stability are identified and isolated in $\mathrm{F}_{9}$ generation starting new breeding stage of the Egyptian cotton breeding program. Abd El-Moghny, 2016; Baloch, et al., 2018; Abdelmoghny, 2021 and Gibely, 2021 a reported that selection in segregating generations is more effective between families rather than within families and selection based on higher heritability is a good indicator to select the best families and the most promising plants within each family in Egyptian cotton crosses. Also, many cotton investigators (AL-Hibbiny et al., 2020; El-Mansy et al., 2020 and Gibley, 2021 b) reported that yield and its components traits had highly significant positive correlation. For that, the cotton breeder can use indirect selection as a good tool to improve these traits. These findings agreed with our findings. So, the present study will focus on lint yield (K/F) as a trait of yield components.

The combined analysis of variance of multi-location yield trials showed significant effects of genotypes and locations as the outward appearance of variation between genotypes; which reflected the diversity of the genetic background for these genotypes. Also, varying growing seasons under different locations and GEI reflected the different performance of genotypes under different locations. These results provide great knowledge for the cotton breeder to determine and select the best and stable cotton genotype. Similar significant differences about the effects of G, E, and GEI were obtained by Abd El-Moghny and Max, 2015 and Abdelmoghny et al., 2019 and 2020 using different phenotypic stability methods to evaluate different Egyptian cotton genotypes in multi locations yield trials under different locations. These results showed that the promising cross [(Giza 89 × A101) x Giza 86] x Giza 94 had superiority across eight crosses and two commercial varieties (Giza 86 and Giza 94), also has long staple fiber quality traits. Then the breeder should estimate stability over different cultivated locations.

The cotton breeder used genotype main effects and genotypes $x$ environments interaction effects (GGE-biplot) technique to estimate phenotypic stability. GGE-biplot is a graphical method that provides an excellent solution to combine the higher yield and stability together. GGE-biplot is the best method that provides a complete picture about megaenvironments, selecting representative and discriminative environments, and appointing more adapted and stable genotypes in specific environments (Yan, 2011). The breeder can order the genotypes from the best genotype (high yield + stable) to the worth one (low yield and unstable) G2, G3, G4, G5, G6, G1, G7 > Grand mean < G8, G9, G10 (Table 2 and Figure 3). Also, arrange the environments from the most desirable to the undesirable as E5 >E1 >E2 > E4 > E3. The obtiened reslut from both combiened analysis of variance and GGE-biblot technique select genotype [(Giza 89 x A101) x Giza 86] x Giza 94 (G2) as the ideal genotype which had higher yied productivity coupled with maximum stability. So that, the cotton breeder can took the hard decision to isolate this genotype to be the new promising cross.

The cotton breeder compare the new cross with two commercial varieties during seven growing seasons (from 2014 to 2020) over five locations and found that the new variety exceed both commercial varieties (Giza 86 and Giza 94) for seed cotton yield, lint yield and lint \% traits as shown in Figures 5, 6 and 7, respectively. The comparison showed that the increase was higher between Giza 97 and Giza 86 than between Giza 97 and Giza 94 . This may be due to the breeder used Giza 94 as the male parent for this new variety and may reflect the lower increasing in lint \% between Giza 97 and Giza 94 which sometimes was non-significant. Giza 97 has an average increase of $12.49 \%$ than Giza 94 and with $28.14 \%$ than Giza 86 for lint yield (K/F) overstudied years and locations. On the other hand, the difference was significant between Giza 97 and Giza 86 for lint \% over the seven years. The three varieties belonging to the long-staple (LS) cotton category, which are characterized by fiber length (30-35) and micronaire value (3.6-4.6) coupled with higher values of fiber strength. The results explained that there are no differences between these varieties and the increasing values had negative or positive values over the seven years. The Egyptian cotton breeder used long-staple lines or varieties to make this cross in 2007 . So, the differences between fiber quality traits was low or did not show highly transgressive segregation in early generations. The targets of cotton breeder for this category are improving yield and its components, lint percentage, and maturity, while maintaining fiber quality traits in the range of the long staple cotton category. The Egyptian breeder succeeded to improve yield as the farmer target, increase lint $\%$ for traders and good fiber quality for spinner. These results help cotton breeder to use the new promising cross [(Giza $89 x$ A101) x Giza 86] x Giza 94 (G2) as a benchmark for selection based on results obtained from combined analysis of variance and GGE-biplot techinque. Starting from the growing season of 2016 the breeder used G2 as a control plus other two commercial varieties (Giza 86 and Giza 94) in multilocations yield trails (LB) and called it as a new promising cross.

Finally, in the growing season of 2017, the cotton breeder took the decision to isolate the new promising cross [(Giza $89 \times$ A101) x Giza 86] x Giza 94, and started the isolated field with only cultivation of selfed seeds for 60 families as individual plants at Sakha Experimental Station as the isolated field (distance was $1.0 \mathrm{Km}$ far from other cotton fields from all directions to avoid cross-pollination). In the 2018 growing season, forming 60 selfed nuclei / 2018 and their natural nuclei were propagated; sixteen of these nuclei were selected according to yielding ability and fiber quality traits to evaluate in a replicated experiment. The natural seeds were used in a variety yield trial to compare their yield with that of the previous foundation seed. The results from the analysis of variance for the variety yield trail during three growing seasons $(208,2019$ and 2020) indicated that all the sixteen nuclei were uniform, homogenous and had high genetic similarity coupled with high yield and stability. Also, the sixteen nuclei had very narrow range of genetic distance or high genetic similarity which reflected the insignificant differences between these nuclei and presented high homogeneity and uniformity (Table 3). The breeder mixed the selected nuclei to perform breeder seeds then multiplicities to increase seed quantity for general cultivation. Through this breeding stage one of the main targets for cotton breeder is to maintain the uniform of plant height, lint colour and seed fuzz by eliminating any off-type plants.

\section{CONCLUSION}

Finally, the new variety Giza 97 is characterized by erect main stem; large size of leaves with deep lobes and leather fell, sympodial branches was medium or long and node of the first fruiting branch ranged from 6-7. Also, lint color is white. The new variety Giza 97 was registered at the variety registration committee after two successful years of DUS tests. After that, 
protection of plant breeder rights was done at Plant Variety Protection Committee, Ministry of Agriculture and Land Reclamation, Egypt under the certificate number 397 using International Union for the Protection of New Varieties of Plants (UPOV) rules. So that, the new variety Giza 97 was recommended for general cultivation in the growing season of 2020.

\section{ACKNOWLEDGEMENT}

The cotton breeders of this new variety are thankful to all the members of Cotton Research Institute for their support and help to release the new variety. Also, many thanks are extended to the Cotton and Fiber Crops Diseases Department, Plant Pathology Research Institute, ARC, The genotypes evaluated in this assay were part of the Cotton Screening Program for Fusarium wilt resistance.

\section{REFERENCES}

Al Didi, M. A. (1972). History of Egyptian cotton varieties. Egypt Cotton Gazette, 58: 36-56.

Al Didi, M. A. (1982). The Egyptian cotton crop 1950-1980. XXXXI Plenary Meeting of the International Cotton Advisory Committee (ICAC). Cairo, Egypt.

Abd El-Moghny, A. M. \& Max. S. Mariz. (2015). Genotypic stability and phenotypic adaptability for some yield traits in some long staple cotton genotypes. Egypt. J. Agric. Res., 93 (1): 85-100.

Abd El-Moghny, A. M. (2016). Genetic analysis and prediction of new recombination in some cotton (G. barbadense L.) crosses. J. Agric. Res. Kafr El-Sheikh Univ. A. Plant Production, 42(3), 319-335.

Abdelmoghny, A. M., Yehia, W. B. \& Max, S. Mariz. (2019). Genotype x environment interaction and stability using AMMI analysis in some Egyptian cotton genotypes. Egyptian J. Plant Breeding, Vol. 23(2): 337-351.

Abdelmoghny, A. M., Gibely, R. H., Max, M. S., Amer, E. A., \& Hassan, S. S. (2021). GGE-Biplot analysis of multienvironments yield trials of Egyptian cotton (Gossypium barbadense L.,). International Journal of Cotton Research and Technology, 2(1), 61-66.

Abdelmoghny, A. M. (2021). Prediction of new genetic recombination in two Egyptian cotton crosses. Egyptian Journal of Agronomy, 43(1): 83-96.

AL-Hibbiny, Y. I. M., Mabrouk, A. H., \& Gibely, H. Reham. (2020). The role of non-allelic interaction in inheritance of some economic traits in G. barbadense. Menoufia Journal of Plant Production, 5(8), 399-410.

Baloch, M. J., Lochi, R., Jatoi, W. A., Baloch, A. W. \& Arain, M. A. (2018). Genetic variability, heritability and correlation studies in $F_{2}$ populations of Upland cotton. Pak. J. Sci. Ind. Res. Ser. B: Biol. Sci. 61b (3):136-144.

EL-Mansy, Y. M., Abdelmoghny, A. M., Gibely, H. Reham, \& Mabrouk, A. H. (2020). Relationship between combining ability, genetic components and genetic diversity using triple test cross in cotton. $16^{\text {th }}$ International Conference Crop Science, Al-Azher University, $13^{\text {th }}-14^{\text {th }}$, October, $53-78$.

Farias, F. J. C., De Carvalho, L. P., Da Silva Filho, J. L., \& Teodoro, P. E. (2016). Biplot analysis of phenotypic stability in upland cotton genotypes in Mato Grosso. Genetics and Molecular Research 15 (2): 1:10.

Fehr, W. I. (1987). Principles of Cultivar Development. Vol. 1. 548 p. Macmillan, New York, USA.

Gibely, H. Reham. (2021 a). Variability, genetic components and selection response in segregating generations among some cotton crosses. Journal Sustainable Agricultural Sciences, 47(1), 1-12.

Gibely, H. Reham. (2021 b). Estimation of genetic variance components and identification of transgressive segregants for two intraspecific extra-long staple cotton crosses. Menoufia Journal Plant Production, 6(1), 53-70.

Gomez, K. A., \& Gomez, A. A. (1984). Statistical Procedures for Agricultural Research. John Wiley \& Sons.

Johnson, R. A., \& Wichern, D. W. (2014). Applied Multivariate Statistical Analysis. (Vol. 6). London, UK: Pearson.

Yan, W., Hunt, L. A., Sheng, Q., \& Szlavnics, Z. (2000). Cultivar evaluation and mega-environment investigation based on the GGE biplot. Crop science, 40(3), 597-605.

Yan, W., \& Kang, M. S. (2002). GGE-Biplot Analysis: A Graphical Tool for Breeders, Geneticists, and Agronomists. CRC press.

Yan, W. (2011). GGE biplot vs. AMMI graphs for genotype-by-environment data analysis. Journal of the Indian Society of Agricultural Statistics, 65(2), 181-193.

Copyright: $(2021$ by the authors. Licensee EJAR, EKB, Egypt. EJAR offers immediate open access to its material on the grounds that making research accessible freely to the public facilitates a more global knowledge exchange. Users can read, download, copy, distribute, print or share a link to the complete text of the application under Creative Commons BY-NC-SA 4.0 International License. 


\section{جيزة 97 صنف قطن مصرى جديد طويل التيلة}

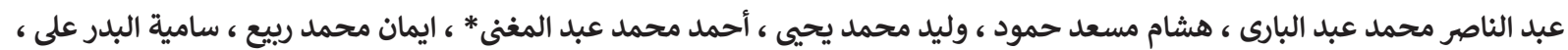

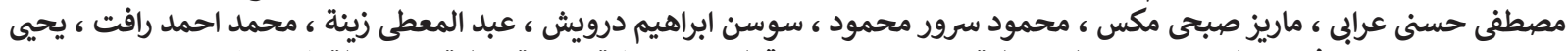

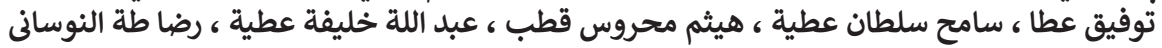

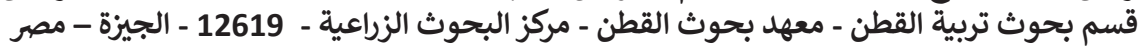
elkomy_a@yahoo.com بريد المؤلف المراسل

الملخص

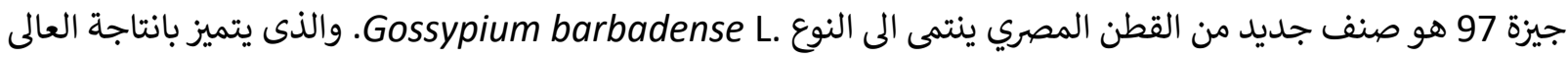

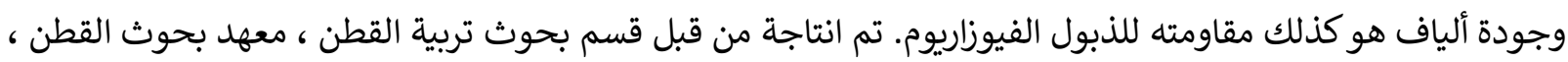

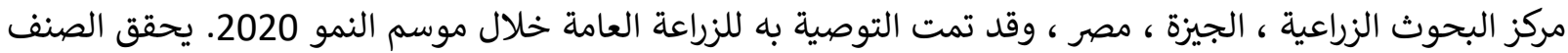

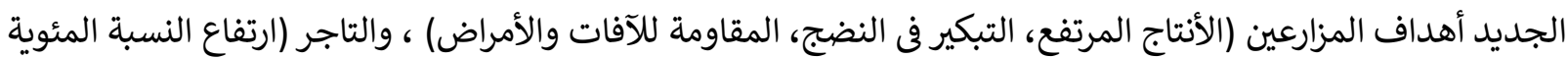

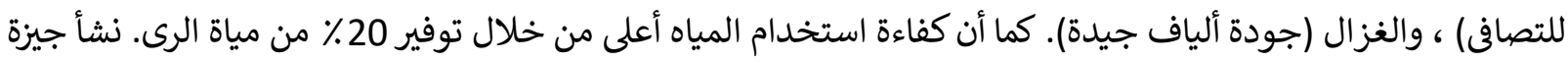

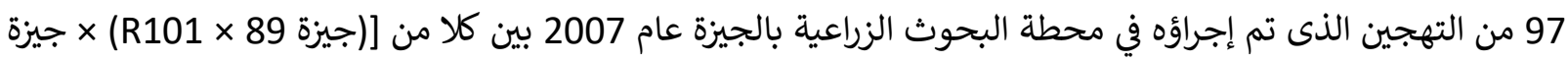

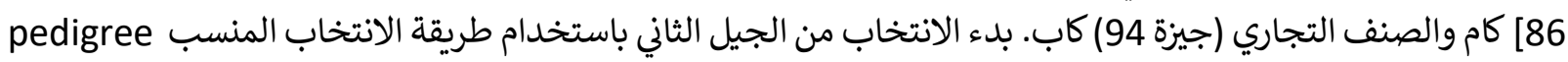

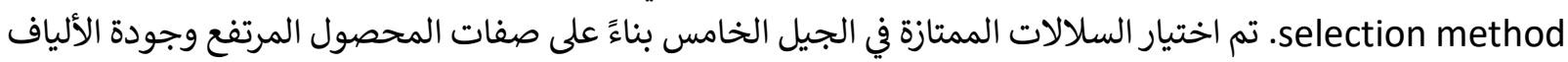

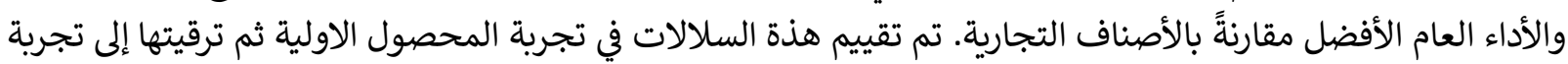

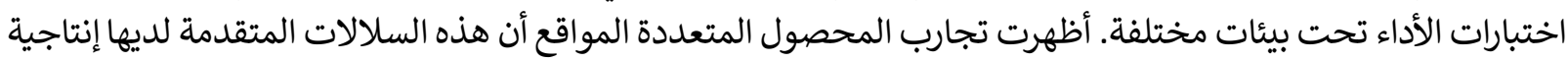

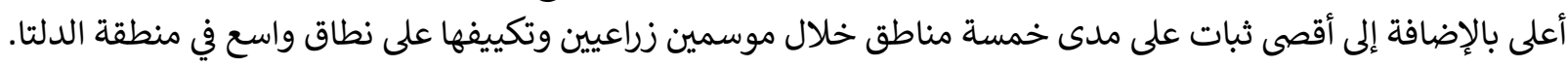

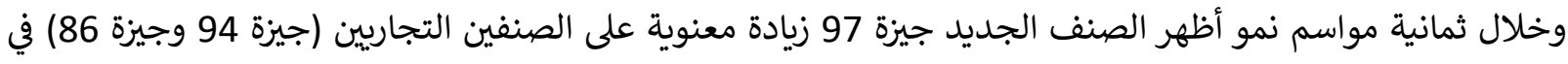

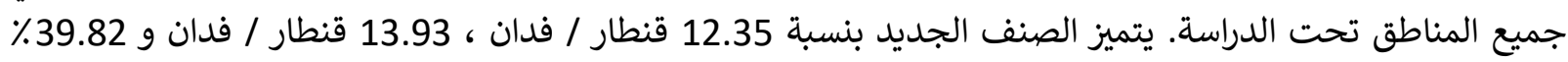

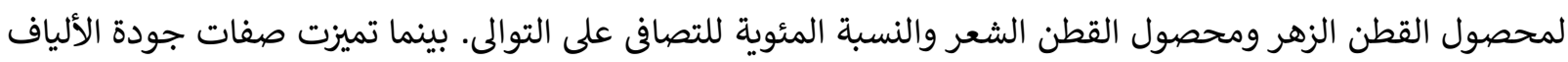

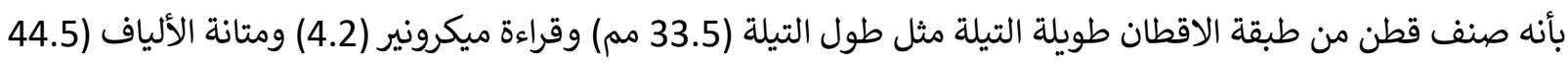
جم / تكس) وانعكاس اللون (8.9) ومتانة الغزل ( 2430) كمتوسط خلان خلال ثلاثة مواسم نمو. الكلمات المفتاحية: قطن مصري ، طويل التيلة ، ثبات ، تجارب متعددة المواقع ، GGE-biplot. 